\title{
The estimation of suspended sediment transport using nefelometric and traditional measurements of turbidity of water on an example of the cascade lower Brda River
}

\author{
Ocena transportu rumowiska zawieszonego z wykorzystaniem \\ nefelometrycznych i tradycyjnych pomiarów mętności wody \\ na przykładzie kaskady dolnej Brdy
}

\author{
Dawid Szatten \\ Uniwersytet Kazimierza Wielkiego w Bydgoszczy
}

Keywords: suspended sediment transport, turbidity of water, total suspension, nefelometric measurements, artificial reservoir

Słowa kluczowe: transport rumowiska zawieszonego, mętność wód, zawiesina ogólna, nefelometryczne pomiary mętności, sztuczne zbiorniki wodne

\begin{abstract}
The evaluation of the suspended sediment transport was conducted on artificial reservoir of cascade of lower Brda River, to compare methods: traditional (weight) and nephelometric (optical). The analysis was based on field research conducted below the Smukała Reservoir in the years 2014 - 2015. These included sample collection for determining the value of total suspension (traditional method) and nephelometric turbidity of water (laser method). Sampling was connected with the observations of water levels, for specifying the hydrological situation. The collected data were interpreted using basic statistical methods. Was found that the Brda River is characterized by a low suspended sediments load. Observations turbidity of water was possible to determine temporary dynamics of suspended sediments and indicate the main source of the suspended material. Received in article data indicate that the compare methods are interchangeability.
\end{abstract}

\section{Streszczenie}

Ocenę transportu rumowiska zawieszonego, dla zbiorników retencyjnych kaskady dolnej Brdy, przeprowadzono w celu porównania metod: tradycyjnej (wagowej) oraz nefelometrycznej (optycznej). Analizy dokonano na podstawie badań terenowych przeprowadzonych poniżej Zbiornika Smukała w latach 2014 - 2015. Obejmowały one pobór prób w celu oznaczenia wartości wskaźnika zawiesina ogólna (metoda tradycyjna) oraz nefelometrycznej mętności wód (metoda laserowa). Pobór połączony był z obserwacjami stanów wody, umożliwiając określenie sytuacji hydrologicznej. Zebrane dane zinterpretowano za pomocą podstawowych metod statystycznych. Stwierdzono, iż rzeka Brda charakteryzuje się niewielkim obciążeniem w materiał zawieszony. Obserwacje zmącenia wód, umożliwiły określenie chwilowej dynamiki zawiesin oraz wskazanie głównego źródła pochodzenia analizowanej składowej transportu fluwialnego. Otrzymane dane wskazują na możliwość zamiennego stosowania porównywanych w artykule metod. 


\section{Wprowadzenie}

Wielkość zmącenia wód w polskich rzekach, możliwa jest do oznaczenia dwoma metodami: tradycyjną, stosowaną za Brańskim (1990) w ramach monitoringu prowadzonego przez IMGW oraz nefelometryczną, coraz częściej stosowaną w badaniach naukowych oraz jakościowych (Clesceri i inni, 1994; Lewis 1996, Sadar, 1996). Pierwsza cechuje się dużą pracochłonnością oraz nakładem kosztów, m.in. na materiały do oznaczeń oraz aparatury do ważenia. Natomiast metoda laserowego oznaczenia zmącenia wód za pomocą mętnościomierzy, jest konkurencyjna ze względu na wysoką dokładność oraz przede wszystkim w wyniku łatwości gromadzenia danych. Celem przeprowadzonych badań była ocena przydatności metody nefelometrycznej $\mathrm{W}$ określeniu transportu rumowiska zawieszonego dla zbiorników retencyjnych należących do kaskady dolnej Brdy. Produkcja energii elektrycznej, warunkuje sztuczny reżim wód poniżej analizowanych stopni wodnych, w wyniku którego następują zrzuty prowadzone w określonej sekwencji. Umożliwia to określenie dynamiki transportu rumowiska zawieszonego $\mathrm{w}$ systemie fluwialnym przekształconym zabudową hydrotechniczną oraz wskazanie przydatności metody nefelometrycznej w określeniu mętności wody.

\section{Metody badań i źródla danych}

Rzeka Brda o długości 245,3 km, stanowiąca lewy dopływ dolnej Wisły, posiada powierzchnię zlewni całkowitej około $4661 \mathrm{~km}^{2}$ (MPHP, 2007). Północna jej część, leżąca na obszarze mezoregionów fizycznogeograficznych, wyznaczonych przez J. Kondrackiego (2002): Równina Charzykowska oraz Bory Tucholskie, cechuje się małymi przekształceniami sieci rzecznej. Natomiast w jej południowej części, zlokalizowano szereg zbiorników retencyjnych: Koronowo - Tryszczyn i Smukała. Pierwszy, zarazem największy z nich (powierzchnia około 1600 ha i pojemność około $81 \mathrm{mln}^{3}$ ) powstał w latach 60-tych XX wieku (Ambrożewski, 2011). Dwa kolejne zbiorniki, retencjonują zdecydowanie mniejszą ilość wód, posiadając odpowiednio powierzchnie 87 ha oraz 94 ha (Studium regionu..., 1953). Wszystkie trzy zbiorniki pracują w jednym systemie kaskadowym (przepływowym), warunkując transport rumowiska Brdy.

Dane służące określeniu mętności wód, zebrano w czasie pomiarów terenowych prowadzonych w latach 2014 - 2015, na stanowisku zlokalizowanym poniżej kaskady dolnej Brdy - wodowskaz Smukała (km 21,0). Badania odbywały się w różnych sytuacjach hydrologicznych, w celu określenia wpływu stopni wodnych na transport rumowiska zawieszonego. Za pomocą geodezyjnie osadzonych łat hydrologicznych, obserwowano w odstępach 5 minutowych, wahania stanu wód. Równocześnie pobierano próby batometrem 
o powolnym napełnianiu według metodyki opisanej przez Brańskiego (1990), do oznaczeń mętności metodą tradycyjną (zawiesina ogólna, $\mathrm{w} \mathrm{mg*1}^{-1}$ ) oraz nefelometryczną (w FNU). Wartości wskaźnika zawiesina ogólna oznaczono w Laboratorium Analiz Jakości Wód Powierzchniowych, Instytutu Geografii Uniwersytetu Kazimierza Wielkiego w Bydgoszczy, według metodyki zawartej w Polskiej Normie (PN-EN 872). Zastosowano sączki celulozowe, których suchą masę oznaczono na wadze analitycznej z dokładnością do 0,2 mg.

Po przesączeniu próbki, przeprowadzono ponowne suszenie i ważenie, w celu określenia suchej pozostałości. Zmącenie wyznaczono według wzoru:

$$
\rho=\underbrace{1000 \times(b-a)}
$$

gdzie:

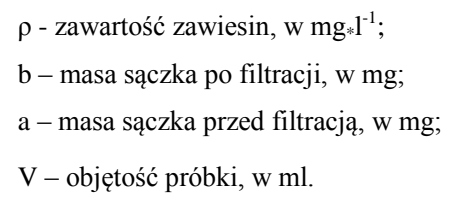

Oznaczenia mętności wód wykonano za pomocą przenośnego mętnościomierza HACH 2100QIS, umożliwiającego dokładny pomiar w zakresie 0 - 1000 FNU. Aparatura spełnia normę ISO-7027, dokonując pomiaru w jednostkach FNU (Formazine Turmidity Unit), który jest identyczny z międzynarodowym standardem NTU (Nephelometric Turbidity Unit).

\section{Wyniki}

Przegrodzenie biegu rzeki powoduje nie tylko zmianę reżimu hydrologicznego ale także ciągłości ruchu rumowiska. $Z$ dotychczas prowadzonych badań na polskich zbiorniach retencyjnych wynika, iż przyczyniają się one do ograniczenia transportu materiału zawieszonego (Łajczak, 1995). Według Z. Babińskiego (2002) Zbiornik Włocławski przechwytuje około $42 \%$ zawiesiny. Tą samą tendencją charakteryzują się zbiorniki kaskady dolnej Brdy, co stwierdzono w badaniach (Jutrowska 2007, Szatten, 2013). Średnioroczna wartość zawiesiny ogólnej dla wielolecia 1969-2013 (dane nie publik. WIOŚ Bydgoszcz oraz badania własne) na stanowisku powyżej pierwszego zbiornika retencyjnego Koronowo ( $\mathrm{km} 75,1 \mathrm{Brdy})$ wynosiła $10,6 \mathrm{mg} \mathrm{l}^{-1}$. Dla punktów obserwacyjnych położonych poniżej tego stopnia wodnego oraz poniżej ostatniego zbiornika Smukała spadły do poziomu odpowiednio $7,5 \mathrm{mg}_{*} \mathrm{1}^{-1}$ oraz $5,3 \mathrm{mg}_{*} \mathrm{1}^{-1}$. Spełniając tym samym wymagania dla bardzo dobrego stanu ekologicznego wód powierzchniowych zgodnie $\mathrm{z}$ obowiązującym rozporządzeniem klasyfikacyjnym (Dz. U. 2014, poz. 1482). Poza stwierdzeniem akumulacyjnej roli zbiorników retencyjnych dolnej Brdy $\mathrm{w}$ transporcie rumowiska zawieszonego, równieinteresującym jest fakt wpływu przekształcenia reżimu hydrologicznego na chwilową 
dynamikę jego transportu. Jak stwierdziły badania Jarockiego (1957) rumowisko zawieszone przemieszcza się w korycie w sposób niejednorodny, poza tym podlega procesowi histerezy (Froehlich 1982; Kostrzewski A. i inni, 1994) związanym z dostawą i/lub wyczerpywaniem materiału do transportu w korycie rzecznym, odnotowanym w relacji przepływ wód/ koncentracja zawiesin.

Na stanowisku poniżej Zbiornika Smukała (ryc. 1), obserwacje rumowiska zawieszonego prowadzone były w czasie różnych sytuacji hydrologicznych. Najwyższe wartości zmącenia charakterystyczne były dla okresu ,zrzutu wód” z elektrowni w czasie produkcji energii (ryc. 1). Pomimo niewielkiego wahania stanów wody $(23 \mathrm{~cm})$, zaobserwowano maksymalne wartości zmącenia dochodzące do ponad 10 FNU. Maksymalna koncentracja transportowanego materiału wyprzedza maksymalny stan (przepływ) wody w korycie. Na tej podstawie wnioskować można, że mamy do czynienia z układem pętlicowym normalnym, odpowiadającym dostawie zawiesin ze zbiornika. Źródło pochodzenia materiału odzwierciedla się poza tym w jego niewielkiej koncentracji. Spracowywanie wody następuje z warstw przydennych zbiornika, które cechują się ich mniejszą koncentracją. Dynamika zawiesin w czasie opadania wód po zrzucie, stanowi kolejną analizowana sytuację hydrologiczną, charakteryzującą się odnotowywaniem niewielkiej mętności, jednakże z licznymi „pikami” (ryc. 1). Zdecydowane zmniejszenie się natężenia przepływu wody przez zaporę, przyczynia się do ograniczenia transportu zawiesin. Odnotowywane zmącenia maksymalne $\mathrm{w}$ tej sytuacji, pochodzą z wymytego przez Brdę materiału, z jej koryta lub strefy brzegu. Jeszcze wyraźniejsze zahamowanie ciągłości transportu rumowiska zawieszonego występuje w przypadku stabilnych stanów wody, gdy odnotowywane wartości zmącenia nie przekraczały 5 FNU. 

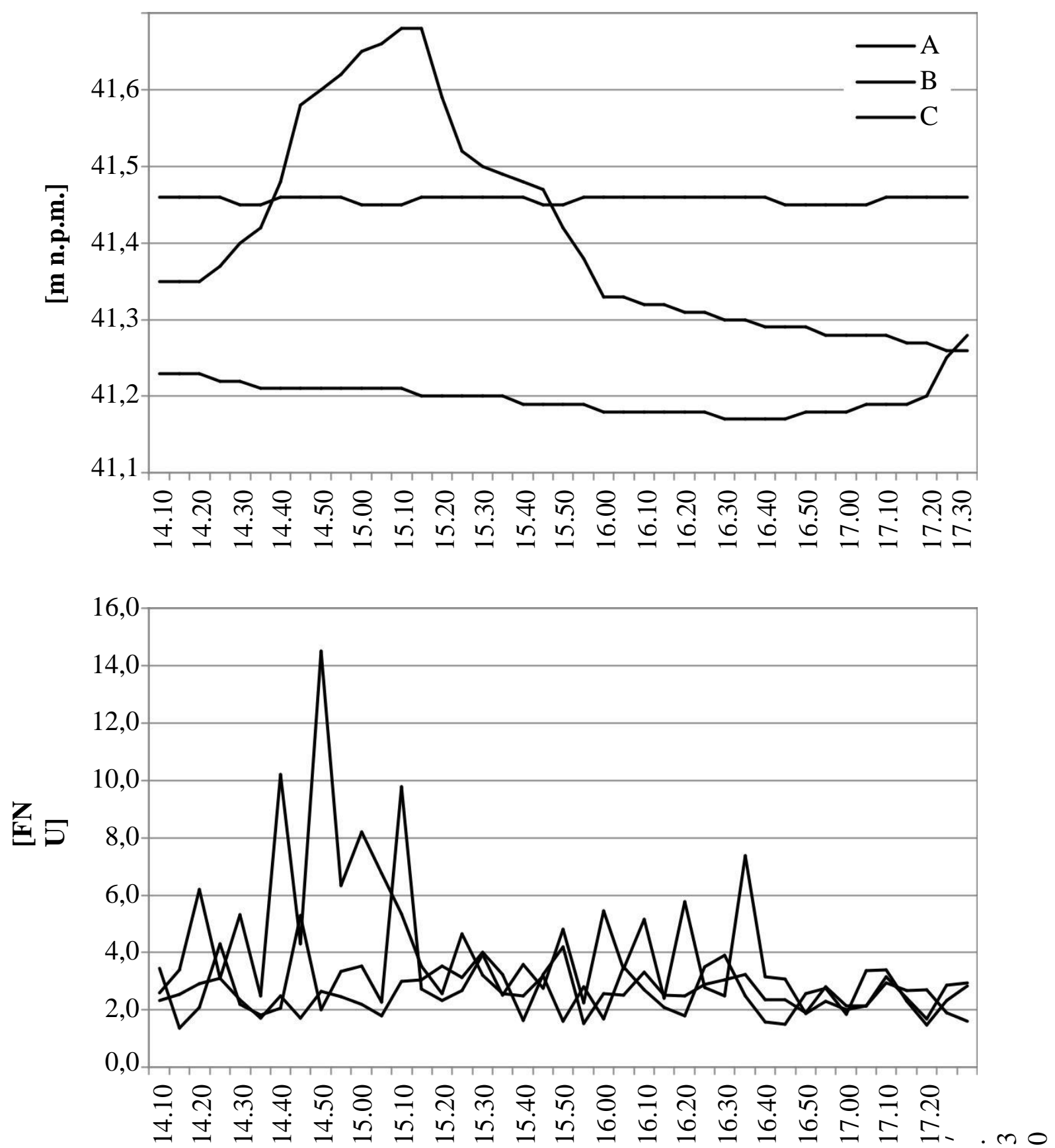

Ryc. 1. Przebieg mętności wód poniżej Zbiornika Smukała w różnych sytuacjach hydrologicznych w czasie badań w latach 2014 - 2015 (A - opadanie stanu wód, B stagnacja stanu wód, C - zrzut wód)

Pomiary prowadzone dwoma metodami: tradycyjną oraz optyczną, umożliwiły obliczenie współczynnika regresji, który przyjmując wartość 0,739 , wskazuje na porównywalność osiąganych wyników, tym samym użyteczność metody nefelometrycznej. Największe odstępstwa od krzywej zauważalne są przy wartościach maksymalnych zmącenia wód (ryc. 2), co wynika z charakteru transportu zawiesin. Ponadto rozbieżności obserwowane 
są przy małych zmąceniach wód, co wymaga dookreślenia pełnej zmienności koncentracji zawiesin za pomocą długiego okresu prowadzenia obserwacji. Jednakże już teraz można stwierdzić, iż określenie dynamiki transportu rumowiska zawieszonego jest możliwe z wykorzystaniem nefelometrycznej skali mętności wód.

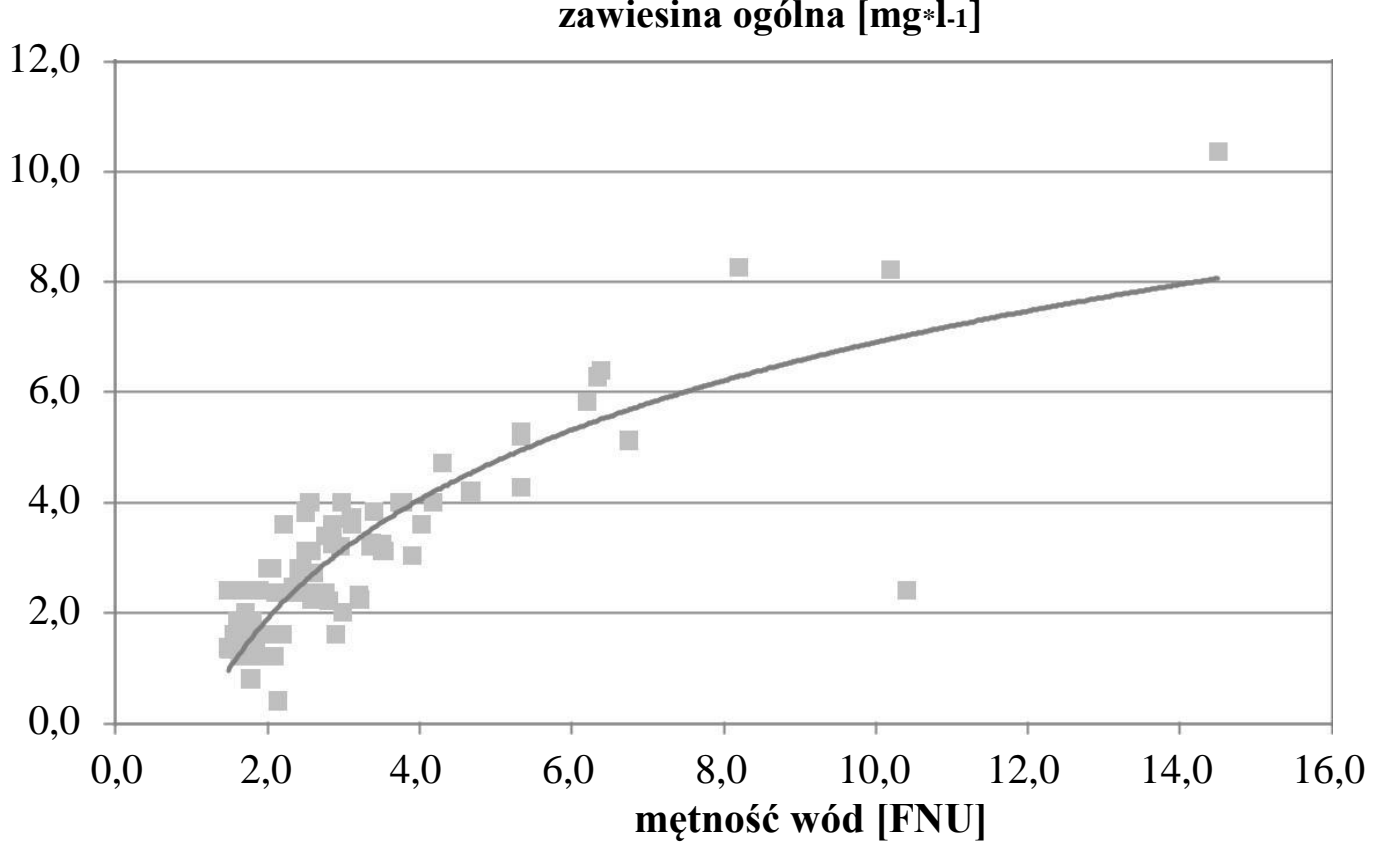

Ryc. 2. Zależność koncentracji zawiesiny ogólnej w wodzie Brdy poniżej zbiorników retencyjnych kaskady dolnej Brdy od mętności w czasie badań w latach 2014 - 2015

\section{Wnioski}

$\mathrm{Na}$ podstawie przeprowadzonych badań $\mathrm{z}$ wykorzystaniem nefelometrycznych i tradycyjnych pomiarów mętności wody, można przedstawić następujące wnioski:

1. Rzeka Brda poniżej kaskady dolnej Brdy, charakteryzuje się niewielkim obciążeniem w materiał zawieszony, co ukazuje wpływ zbiorników retencyjnych na ciągłość transportu rumowiska (rola akumulacyjna).

2. Obserwacje zmącenia wód, prowadzone czasie różnych sytuacji hydrologicznych, umożliwiają określenie chwilowej dynamiki zawiesin, wskazującej źródło pochodzenia materiału zawieszonego (układ pętlicowy normalny - dostawa ze zbiornika).

3. Zależność koncentracji zawiesiny ogólnej, reprezentującą metodę tradycyjną oraz mętności wód, w skali nefelometrycznej, została określona na poziomie współczynnika regresji 0,739 , wskazując na użyteczność i możliwość zamiennego stosowania porównywanych w artykule metod. 


\section{Literatura}

1. Ambrożewski Z. J., 2011. 50 lat zbiornika i elektrowni wodnej Koronowo [W:] Gospodarka Wodna. Wyd. Sigma Not, Warszawa, 12, 512-519.

2. Babiński Z., 2002. Wpływ zapór na procesy korytowe rzek aluwialnych ze szczególnym uwzględnieniem stopnia wodnego Włocławek. Wyd. Akademii Bydgoskiej im. Kazimierza Wielkiego, Bydgoszcz, ss.185.

3. Brański J., 1990. Instrukcja wykonywania i opracowania pomiarów rumowiska unoszonego. Instytut Meteorologii i Gospodarki Wodnej, Warszawa.

4. Clesceri L. S., Greenberg A. E., Eaton A. D. (Eds.), 1994. Standard Methods for the Examination of Water and Wastewater. XX Ed. American Public Health Association. Washington.

5. Dane nie publik. WIOŚ Bydgoszcz, 1969-2013 - wyniki Państwowego Monitoringu Środowiska, wart. wskaźnika zawiesina ogólna dla stanowisk poniżej zbiorników retencyjnych kaskady dolnej Brdy.

6. Froehlich W., 1982. Mechanizm transportu fluwialnego i dostawy zwietrzelin do koryta w górskiej zlewni fliszowej. Prace Geogr. IGiPZ PAN, ss.144.

7. Jarocki W., 1957. Ruch rumowiska w ciekach. Badanie oraz obliczanie ilości materiału wleczonego i unoszonego. Wyd. Morskie, Gdynia, ss.356.

8. Jutrowska E., 2007. Antropogeniczne zmiany warunków hydrologicznych w dorzeczu Brdy. Biblioteka Monitoringu Środowiska, Bydgoszcz.

9. Kondracki J., 2002. Geografia regionalna Polski. Wydawnictwo Naukowe PWN, Warszawa, ss.441.

10. Kostrzewski A., Mazurek M., Zwoliński Z., 1994. Dynamika transportu fluwialnego górnej Parsęty jako odbicie funkcjonowania systemu zlewni. Stowarzyszenie Geomorfologów Polskich, Poznań.

11. Lewis J., 1996. Turbidity-controlled suspended sediment sampling for runoff-event load estimation. Water Resources Research, 32(7), 2299-2310.

12. Łajczak A, 1995. Studium nad zamulaniem wybranych zbiorników zaporowych w dorzeczu Wisły. Monografie Komitetu Gospodarki Wodnej PAN, 8

13. Polska Norma PN-EN 872, 2007. Jakość wody. Oznaczanie zawiesin. Metoda z zastosowaniem filtracji przez sączki z włókna szklanego. Polski Komitet Normalizacyjny, Warszawa.

14. Rastrowa Mapa podziału hydrograficznego Polski (MPHP), 2007. Zakład Hydrografii i Morfologii Koryt Rzecznych. IMGW, Warszawa.

15. Rozporządzenie Ministra Środowiska z dnia 30 października 2014 r. w sprawie sposobu klasyfikacji stanu jednolitych części wód powierzchniowych oraz środowiskowych norm jakości dla substancji priorytetowych, poz. 1482 (Dz. U. 2014, poz. 1482).

16. Sadar M. J., 1996. Turbidity science. Technical Information Series Booklet No. 11. HACH Technical Center for Applied Analytical Chemistry. Loveland.

17. Studium regionu doliny Brdy, 1953. Biuro Planów Regionalnych, Warszawa.

18. Szatten D., 2013. Wpływ powstania Zbiornika Koronowskiego na hydrografię obszarów przyległych. Zeszyty Naukowe Uczelnianej Rady Doktorantów UKW, I, 73-92. 